\title{
Estimation of Pancreatic IRI Output Rate and Its Relation to Glucose Tolerance in Normal Anaesthetized Dogs
}

\author{
U. Fischer, H. Hommel, H.-D. Gottschling, P. Heinke and E. Jutzi \\ Central Institute for Diabetes "Gerhardt Katsch" Karlsburg, German Democratic Republic \\ Received: August 31, 1974, and in revised form: May 15, 1975
}

\begin{abstract}
Summary. The pancreaticoduodenal and portal venous blood flows were recorded electromagnetically in anaesthetized dogs. Blood glucose and IRI were measured in the arterial, portal, and peripheral venous as well as in the intestinal venous blood. By a mathematical model the actual net IRI output of the whole pancreas was estimated. Under basal conditions it is $10.2 \pm 2.4 \mathrm{mU} / \mathrm{min}$ ( $\mathrm{n}=30 ; 26 \mathrm{~kg}$ mean body wt.). After i.v. glucose injection, IRI output is rapidly enhanced. The biphasic nature of this reaction was unequivocally demonstrated by consideration of the ratio IRI output : blood glucose. Pancreaticoduodenal blood flow increases transiently in relation to the increased blood glucose concentration. The IRI secretion rate is well correlated with the blood glucose concentration and to the amounts of glucose or of blood reaching the whole pancreas. It is also correlated with the portal IRI concentration. The overall peripheral venous or arterial IRI concentrations are correlated with the IRI secretion rate, but not in all
\end{abstract}

individual experiments. The different phases of IRI output (basal rate, stimulated output $1-10 \mathrm{~min}$ and $10-60 \mathrm{~min}$ ) show no influence on each other, nor are they correlated with the peripheral IRI concentration area. Basal IRI output is negatively correlated with the glucose assimilation constants. These constants or the peripheral BG areas, however, are independent of the stimulated IRI output rate. However, both the assimilation constants and the peripheral BG areas are related to the peripheral IRI concentration areas. Hepatic uptake of insulin and dynamics of pancreatic blood flow seem to contribute considerably to the estimated correlation pattern.

Key words: Insulin secretion rate, pancreatic blood flow, mathematic model, IRI concentration, blood glucose, glucose assimilation, dog.
By means of insulin analyses in peripheral venous blood during diagnostic tests the description of well defined groups of patients and their allocation to hypothetical developmental stages of diabetes mellitus are possible [8]. However, due to the hepatic uptake of insulin, these measurements cannot give an exact pancreatic insulin secretion rate [11].

There have been attempts to estimate the rate of insulin secretion by indirect methods: the evaluation of the rate of degradation of insulin under steady state conditions $[2,11,45]$; the comparison of plasma IRI values after a rapidly acting secretory stimulus with those after an exogenous insulin load [41]; and the estimation according to a "reciprocal" indicator dilution principle with insulin as an indicator [46]. Repeated estimations, however, are not possible by these methods.

Insulin release in vivo can be evaluated better from the pancreatic blood flow and the pancreatic arteriovenous difference of insulin concentration. Kanazawa et al. [21], Lefebvre and Luyckx [24] and Porte et al. [33] estimated the IRI secretion rate of anaesthetized dogs by sampling superior pancreaticoduodenal vein. In that experimental arrangement, however, the pancreatic blood stream could be altered and only a part of the pancreas is considered.
Data on pancreatic blood flow under sufficiently physiological conditions can be obtained with the electromagnetic method [37]. We measured pancreaticoduodenal and portal flows by this method [12]. Blood samples were obtained from the portal vein instead of the pancreaticoduodenal vein, for the calculation of insulin secretion. The actual net IRI output was estimated by a mathematic model. In this paper we consider the relationship between IRI output and concentration as well as the influence upon it of blood glucose concentration and of whole pancreatic glucose supply in normal anaesthetized dogs.

\section{Material and Methods ${ }^{1}$}

\section{Experimental Design}

16 Alsatian dogs of both sexes were anaesthetized using intubation and artificial breathing (hexobarbital sodium/nitrous oxide/oxygen, relaxation with Myorelaxin $^{\circledR}$, constant i.v. infusion of $0.9 \%$ saline 2.0

1 Abbrevations: $\mathrm{BG}=$ blood glucose, $\mathrm{IRI}=$ immunoreactive insulin activity, Indices: art $=$ arterial, ven $=$ peripheral venous, int $=$ intestinal venous, port $=$ portal venous. $F_{1}$ in the formulas $=$ blood flow through the A. pd. sup. 
$\mathrm{ml} / \mathrm{min}$ ): mean body wt. was $26.6 \pm 0.8 \mathrm{~kg}$, starvation $20 \mathrm{hrs}$ at the beginning of anaesthesia, mean time from the beginning of anaesthesia to the injection of glucose $180 \mathrm{~min}$. Heparin was not used.

During laparotomy the animals were prepared in the following way: flowprobes of an electromagnetic flowmeter at the superior pancreaticoduodenal artery and, in some experiments, at the trunk of the portal vein; catheters for drawing blood in the portal vein within the liver via the splenic vein, in the ileocolic or jejunal veins ("intestinal veins"), and in the femoral and the saphenous veins; a catheter for recording the blood pressure in the splenic artery up to the coeliac artery. The operative procedure has been described in detail by Fischer et al. [12].

The animals were injected intravenously with $0.125,0.25$ or $0.5 \mathrm{~g} / \mathrm{kg}$ glucose within $25 \mathrm{sec}(1.25$ $\mathrm{ml} / \mathrm{kg}$ of solutions with 10,20 or $40 \mathrm{~g}$ glucose in 100 $\mathrm{ml})$. BG and plasma IRI concentrations in the peripheral vein $\left(\mathrm{BG}_{\mathrm{ven}}, \mathrm{IRI}_{\mathrm{ven}}\right)$, portal vein $\left(\mathrm{BG}_{\mathrm{port}}\right.$, IRIport $)$, intestinal veins $\left(B G_{\text {int }}, I R I_{\text {int }}\right)$ and in the femoral artery $\left(\mathrm{BG}_{\mathrm{art}}, \mathrm{IRI}_{\mathrm{art}}\right)$ have been analyzed simultaneously at the following times: - $15,-1,1,2,3,4,5,6$, $7,8,9,10,15,20,25,30,40,50,60$ and $90 \mathrm{~min}$ (for the analytical methods cf. Fischer et al. [15]).

Pancreaticoduodenal and portal blood flows (square wave flowmeter Nycotron A/S, Drammen, Norway), heart frequency and mean arterial blood pressure (Biometer BM 101 RFT, VEB Meßgerätewerk Zwönitz, GDR) were continuously recorded (Motorkompensator MK, VEB Medizingerätewerk "Erich Weinert", Magdeburg, GDR).

\section{Methodological Observations}

General anaesthesia and laparotomy can be followed by a depression of insulin secretion and of glucose tolerance [13]. Part of this depression is produced by autonomic blocking agents used for premedication. Therefore these drugs have been omitted from our experiments.

The integrity of the pancreatic vascular nervous system was proved by the normal reaction of the blood flow to irritation of the arterial chemoreceptors by intravenous injection of potassium cyanide (short lasting increase and long lasting decrease thereafter). Blood flows through both the superior mesenteric and the common hepatic arteries were not altered by the whole experimental arrangement. Portal venous flow can only be measured by this method when no catheter is inserted into this vessel. Therefore, data on portal venous and simultaneous pancreaticoduodenal arterial flows were obtained in a group of preliminary experiments without analysis of IRI $_{\text {port }}$. The ratio between both these flow rates was not significantly altered by the test [12].

IRI $_{\text {int }}$ is significantly smaller than IRI $_{\text {ven }}$ or IRI art $_{\text {t }}$ [12]. Therefore, in this arrangement the estimation of IRI $_{\text {int }}$ has been necessary. Neither in the different catheters nor at the different times before and after the tests did the hematocrit show significant alterations [12]. Thus, for these evaluations the mean of all hematocrit measurements has been used ( $49.5 \pm 0.5$, $\mathrm{n}=168)$. - After the injection of China ink into the v. pancreaticoduod. sup. we found the color evenly distributed in all parts of the liver. This fact indicates a turbulent blood stream in the portal vein under these conditions and a sufficient mixing of the pancreaticoduodenal stream with the other splanchnic blood.

\section{Estimation of the IRI Output Rate}

Several constants had to be used for the mathematic evaluation. They had been estimated experimentally: The part of the pancreas supplied by the superior pancreaticoduodenal artery amounts to $58 \pm 2 \%$ of the wet weight (injection of China ink). The reciprocal value of this is the constant $K_{1}$.

According to preliminary estimations less than 5\% of the pancreaticoduodenal flow passes through the duodenal mucosa. That part has been neglected. The part of the whole portal blood flow reaching the splanchnic area via the superior pancreaticoduodenal artery amounts to $9.5 \pm 0.4 \%$. The reciprocal value of this is the constant $\mathrm{K}_{2}$. It does not change significantly after glucose injection [12]. $\mathbf{K}_{4}=$ $(100$-hematocrit $) / 100=0.505$.

The actual net IRI output of the whole pancreas is - as an approach - the difference between the amount of IRI passing the trunk of the portal vein and the amounts reaching the whole pancreas at its arterial side and leaving the non-pancreatic organs of the splanchnic area:

The portal entrance of the liver is passed by

$\mathrm{F}_{1} \cdot \mathrm{K}_{2} \cdot \mathrm{IRI}_{\text {port }} \cdot \mathrm{K}_{4}[\mu \mathrm{U} / \mathrm{min}]$

The whole pancreas is reached by

$\mathrm{F}_{1} \cdot \mathrm{K}_{1} \cdot \mathrm{IRI}_{\text {art }} \cdot \mathrm{K}_{4}[\mu \mathrm{U} / \mathrm{min}]$ All other organs of the splanchnic area deliver venously

$\left(\mathrm{F}_{1} \cdot \mathrm{K}_{2}-\mathrm{F}_{1} \cdot \mathrm{K}_{1}\right) \cdot \mathrm{IRI}_{\mathrm{int}} \cdot \mathrm{K}_{4}[\mu \mathrm{U} / \mathrm{min}]$

The difference (I) - (II) - (III) is

$\mathrm{F}_{1} \cdot \mathrm{K}_{4}\left[\mathrm{~K}_{2}\left(\mathrm{IRI}_{\text {port }}-\mathrm{IRI}_{\mathrm{int}}\right)+\mathrm{K}_{1}\left(\mathrm{IRI}_{\mathrm{int}}-\mathrm{IRI}_{\mathrm{art}}\right)\right]$ [ $\mu \mathrm{U} / \mathrm{min}]$ (IV). The amount of glucose reaching the whole pancreas arterially is

$\mathrm{F}_{1} \cdot \mathrm{BG}_{\mathrm{art}} \cdot \mathrm{K}_{1} / 100[\mathrm{mg} / \mathrm{min}]$

Additionally, the following parameters were calculated: $\mathrm{K}=$ glucose assimilation constant [9]; 


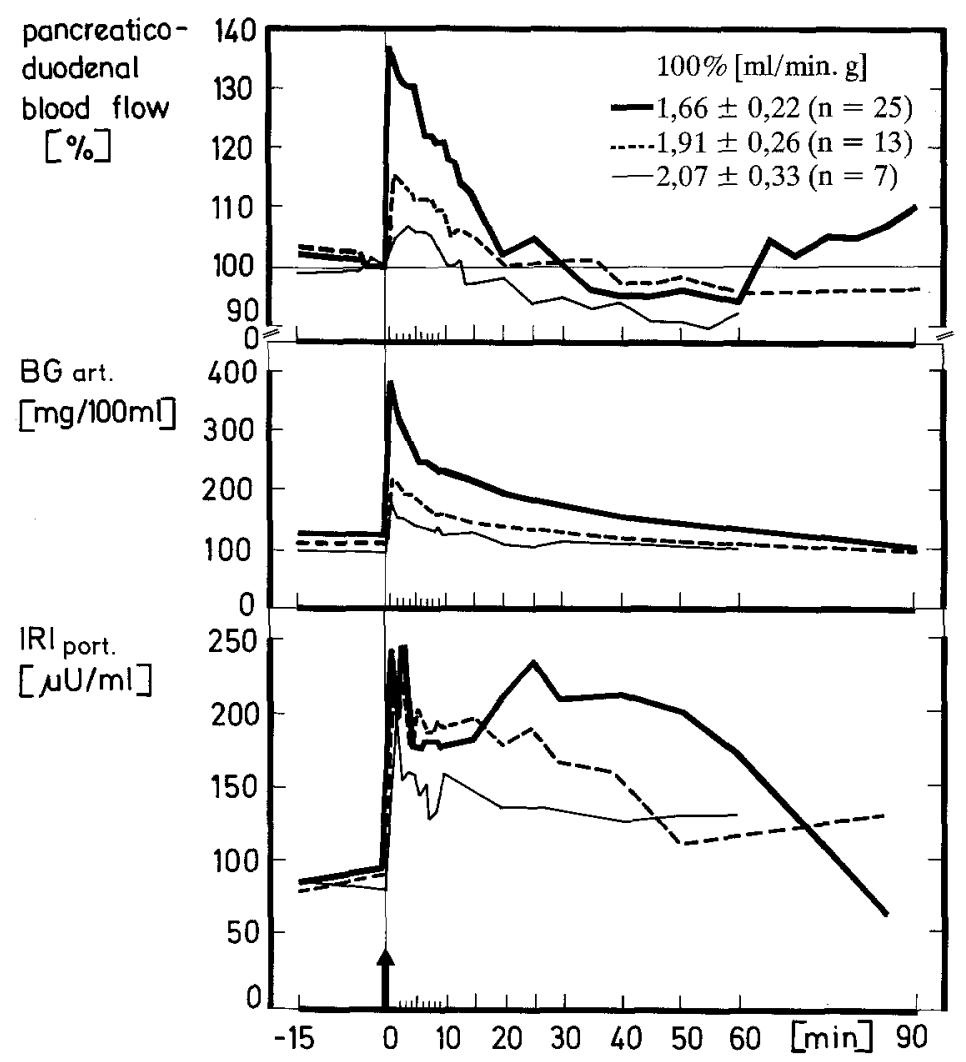

Fig. 1. Mean pancreaticoduodenal blood flow, $B G_{\text {art }}$ and $I R I_{\text {port }}$ in anaesthetized dogs before and after iv. injection of $0.5(-, n=7), 0.25$ $(-\cdots, n=5)$ or $0.125(-, n=4) \mathrm{g} / \mathrm{kg}$ glucose. Evaluation of the blood flow: value at $-1 \mathrm{~min}=100 \%$, from -5 to $+15 \mathrm{~min}$ the value for each min was taken from the registered curves, for the remaining time one value was obtained for every $5 \mathrm{~min}$

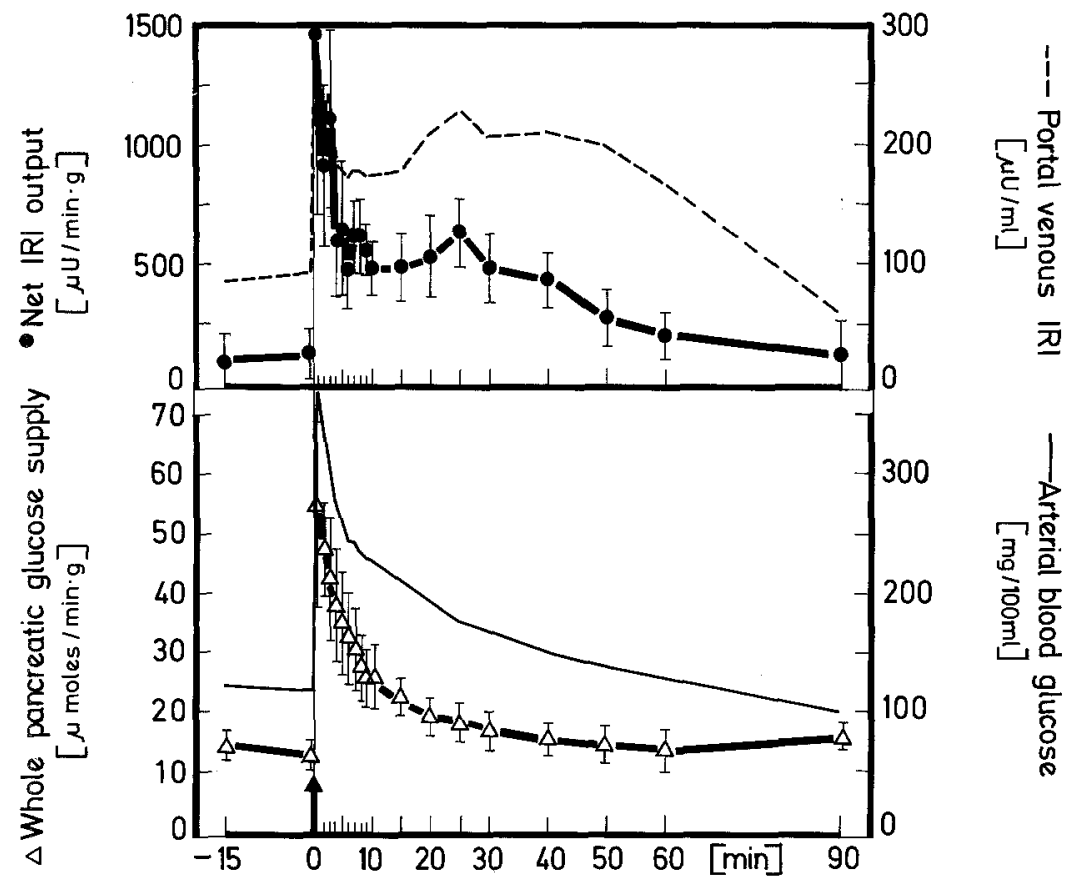

Fig. 2. Mean arterial blood glucose concentration and estimated glucose inflow into the whole pancreas (lower part), and portal venous IRI concentration and estimated IRI output from the whole pancreas (upper part) in 7 dogs before and after the rapid injection of $0.5 \mathrm{~g} / \mathrm{kg}$ glucose 
areas of $B G$ from the time of glucose injection up to the BG normalization, and of IRI $(0-10$ and $10-60$ $\mathrm{min})$ in the peripheral venous and arterial blood.

All estimates were made on the computer Cellatron 8205 (VEB Kombinat Centronik, Meiningen, GDR). Statistical distribution as well as multiple correlations of analytic data and of calculated parameters have been investigated.

The mean values \pm SEM are given. Significance levels of $P<0.01$ and of $P<0.05$ were required.

\section{Results}

Before the tests the BG pattern at the different points showed the well known arteriovenous concentration difference of about $10 \mathrm{mg} / 100 \mathrm{ml}$. From 2-15 min after the injection of glucose this difference was enhanced. Its alteration, however, was very small. In 357 non-selected pairs of data (before and after the injection of all doses of glucose) the BG values in the various explored vessels are related by the following equations:

$$
\begin{aligned}
& \mathrm{BG}_{\text {art }}=1.04 \cdot \mathrm{BG}_{\text {ven }}+1.0(\mathrm{r}=0.95) \\
& \mathrm{BG}_{\text {int }}=0.99 \cdot \mathrm{BG}_{\text {art }}+2.2(\mathrm{r}=0.96) \\
& \mathrm{BG}_{\text {art }}=0.97 \cdot \mathrm{BG}_{\text {port }}+10.2(\mathrm{r}=0.93)
\end{aligned}
$$

Therefore only $\mathrm{BG}_{\mathrm{art}}$ is given in Figs. 1 and 2 . Immediately after an increased $B G$ the pancreaticoduodenal blood flow rose rapidly (Fig. 1). Thus the increase is not proportional to the actual BG level, as can be seen by the alteration of their ratio (Fig. 5).

Some dependence, however, of the relative flow increase (both amount and duration) on the injected dose is to be seen.

The actual glucose supply (= inflow into the whole pancreas) has been estimated (one group is presented in Fig. 2 as an example) because at present that of the islets of Langerhans cannot be analyzed directly. With respect to the small portion of the endocrine tissue of the whole pancreas and provided that the specific blood supply of the endocrine and of the exocrine tissues are similar, about $2-4 \%$ of the amounts of glucose given in Fig. 2, are at the disposal of the islets of Langerhans.

The IRI concentrations in the various vessels are related by the following equations $(n=250$ non-selected pairs of data in the range from $2-237 \mu \mathrm{U} / \mathrm{ml}$ of $\mathrm{IRI}_{\text {art }}$ ):

$\mathrm{IRI}_{\mathrm{art}}=0.97 \cdot \mathrm{IRI}_{\mathrm{ven}}+5.4(\mathrm{r}=0.90)$;

$\mathrm{IRI}_{\text {int }}=0.51 \cdot \mathrm{IRI}_{\text {art }}+21.7(\mathrm{r}=0.83)$;

$\mathrm{IRI}_{\mathrm{art}}=0.36 \cdot \mathrm{IRI}_{\text {port }}+17.7(\mathrm{r}=0.60)$;

Fig. 3 shows these relations after the injection of 0.5

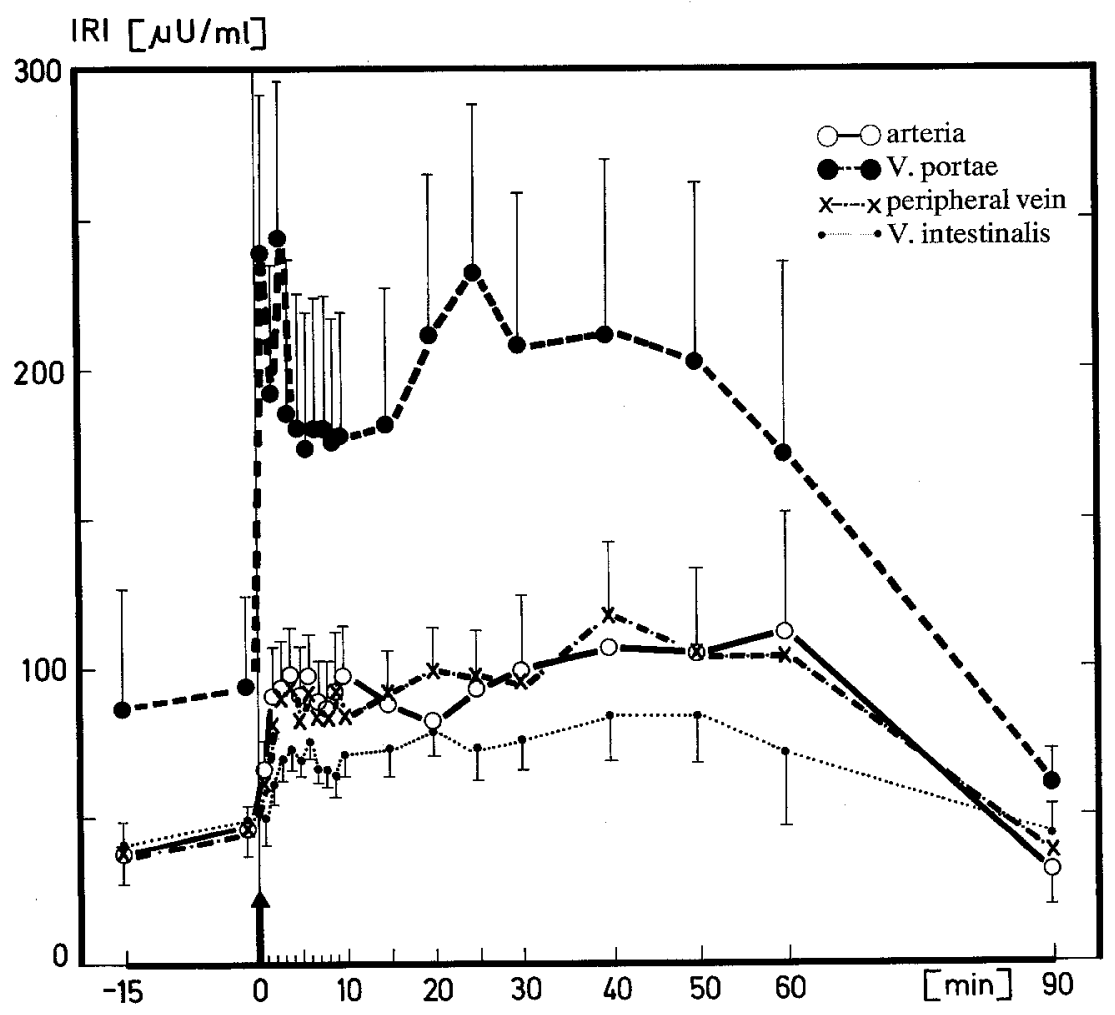

Fig. 3. Arterial $(\bigcirc)$, portal venous $(\bullet)$, peripheral venous $(\times)$ and intestinal venous $(\bullet)$ plasma IRI concentrations in anaesthetized dogs before and after iv. injection of $0.5 \mathrm{~g}$ glucose per $\mathrm{kg}$ 
Table 1. Glucose assimilation constants of the arterial $\left(K_{a r}\right)$ and peripheral venous $\left(K_{v e n}\right)$ blood glucose data, arterial and peripheral venous $B G$ areas /mmoles $\cdot \min / l]$ up to the time of $B G$ normalization, arterial and peripheral venous IRI areas for $1-10$ and $10-60 \mathrm{~min}[\mu \mathrm{U} \cdot \mathrm{min} / \mathrm{ml}]$, and additional IRI output (stimulated minus basal rate) during the test $1-10 \mathrm{~min}[\mathrm{mU} / 10 \mathrm{~min}$ ] and 10 - $60 \mathrm{~min}$ ( $\mathrm{mU} / 50 \mathrm{~min}$ ) in anaesthetized dogs after intravenous injection of different doses of glucose

\begin{tabular}{|c|c|c|c|c|c|c|}
\hline \multirow{3}{*}{$\mathrm{n}$} & \multicolumn{2}{|c|}{$0.5 \mathrm{~g} / \mathrm{kg}$} & \multicolumn{2}{|c|}{$0.25 \mathrm{~g} / \mathrm{kg}$} & \multicolumn{2}{|c|}{$0.125 \mathrm{~g} / \mathrm{kg}$} \\
\hline & 7 & & 5 & & 4 & \\
\hline & mean & SEM & mean & SEM & mean & SEM \\
\hline body wt. [kg] & 25.3 & 1.0 & 27.0 & 1.4 & 27.4 & 2.4 \\
\hline $\begin{array}{l}\mathbf{K}_{\text {art }} \\
\mathbf{K}_{\text {ven }} \\
\text { BG-area }_{\text {axt }} \\
\text { BG-area }\end{array}$ & $\begin{array}{l}2.0 \\
1.8 \\
211 \\
205\end{array}$ & $\begin{array}{l}0.2 \\
0.1^{\mathrm{a}} \\
30^{\mathrm{a}} \\
20\end{array}$ & $\begin{array}{l}1.8 \\
1.2 \\
72 \\
98\end{array}$ & $\begin{array}{l}0.2 \\
0.1 \\
22 \\
30\end{array}$ & $\begin{array}{l}1.5 \\
1.1 \\
53 \\
49\end{array}$ & $\begin{array}{c}0.3 \\
0.1 \\
7 \\
13\end{array}$ \\
\hline $\begin{array}{l}\text { IRI-area }_{\text {art }} \\
0-10 \mathrm{~min} \\
10-60 \mathrm{~min} \\
\text { IRI-area }_{\text {ven }} \\
0-10 \mathrm{~min} \\
10-60 \mathrm{~min}\end{array}$ & $\begin{array}{r}420 \\
3170 \\
\\
390 \\
3120\end{array}$ & $\begin{array}{l}120 \\
970 \\
\\
110 \\
960\end{array}$ & $\begin{array}{r}500 \\
2390 \\
\\
540 \\
2830\end{array}$ & $\begin{array}{r}250 \\
1380 \\
\\
230 \\
1500\end{array}$ & $\begin{array}{l}150 \\
270 \\
\\
160 \\
600\end{array}$ & $\begin{array}{c}90 \\
150^{\mathrm{a}} \\
\\
80 \\
260^{\mathrm{a}}\end{array}$ \\
\hline $\begin{array}{l}\text { additional } \\
\text { IRI output } \\
1-10 \mathrm{~min} \\
10-60 \mathrm{~min}\end{array}$ & $\begin{array}{l}381 \\
758\end{array}$ & $\begin{array}{l}143 \\
259\end{array}$ & $\begin{array}{l}405 \\
491\end{array}$ & $\begin{array}{l}101 \\
271\end{array}$ & $\begin{array}{l}345 \\
578\end{array}$ & $\begin{array}{r}52 \\
611\end{array}$ \\
\hline
\end{tabular}

${ }^{a}$ significant differences to the other data of that line $(p<0.01)$

$\mathrm{g} / \mathrm{kg}$ glucose. During the rapid alteration in the first test phase all other concentrations cannot exactly reflect the portal one. The difference of IRI ${ }_{\text {int }}$ from the other values increased after stimulation of insulin secretion. The animals loaded with smaller doses of glucose reacted in a similar way.

The basal net IRI output rate at a mean interval of $180 \mathrm{~min}$ from the onset of anaesthesia amounted to $10.2 \pm 2.4 \mathrm{mU} / \mathrm{min}$ in 30 animals (mean body wt. $26.0 \pm 0.8 \mathrm{~kg}$ ). This is about $280 \mu \mathrm{U} / \mathrm{min} \cdot \mathrm{g}$. After glucose injection it is enhanced rapidly (Figs. 2 and 4). The early increase does not clearly depend on the BG alteration (Table 1). This phase is followed by a plateau, the level and the duration of which seem to be related to hyperglycemia. The enhancement of IRI output, however, lasts longer than that of BG.

The biphasic insulin secretion shown in the concentration pattern of IRI port (Fig. 3) seems to become obscured by the computation (Fig. 4). Fig. 5 demonstrates a distinct biphasic reaction if the relation of the estimated net IRI output to the actual BG concentration or to the blood flow is considered. In relation to the amount of glucose actually reaching the pancreas IRI output increases significantly only in the later test phase. Before the glucose load, about $14 \cdot 10^{-6}$ moles IRI are liberated per mol glucose assumed to reach the endocrine pancreas. If the load is reduced, the difference of this ratio between both phases shown in Fig. 5 became smaller. Multiple correlations between all measured and calculated values have been investigated both for each individual experiment and for all data together. Net IRI output, glucose concentration, and pancreatic glucose supply are well correlated $(p<0.01)$. In Fig. 6 this fact is documented by the relationship between the relative IRI output rate and the relative glucose inflow into the pancreas. Pancreaticoduodenal blood flow and IRI output are loosely related. Both these parameters depend strongly on an additional factor: the BG alteration. Any IRI concentration represents IRI output rate in a varying portion of the individual tests only. The highest level of significance $(p<0.01)$ exists in the relation of IRI output to IRI $_{\text {port }}$. Peripheral venous or arterial IRI concentrations cannot give an exact figure of insulin secretion.

There is some correlation between these parameters in total, but it is absent in most of the individual experiments. This is demonstrated in Fig. 7 in two selected animals, only one of which has a significant 
IRI output, $\%$ of initial value

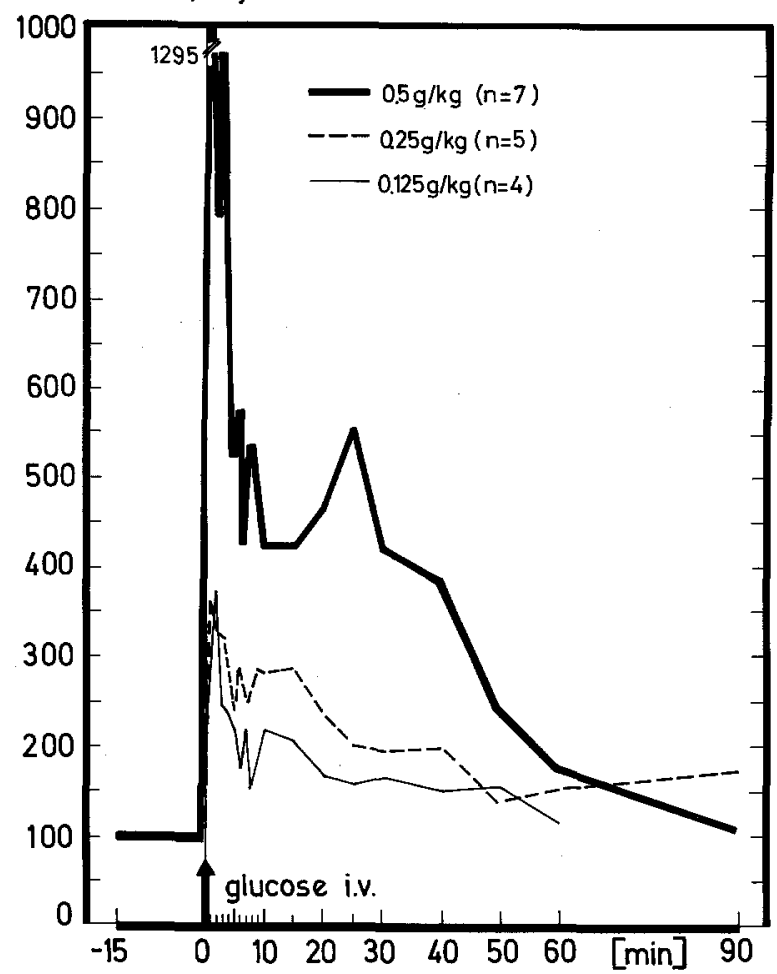

Fig. 4. Mean relative rate of IRI output from the canine pancreas after the rapid iv. injection of different doses of glucose. $100 \%=$ mean of the -15 and -1 min-values in the individual experiments

correlation of IRI $\mathrm{ven}_{\text {ven }}$ with IRI output whereas $\operatorname{IRI}_{\text {port }}$ is closely related to insulin secretion.

Finally, correlation analysis has been performed, independent of the dose administered, between pancreatic IRI output rate, and some parameters, usually estimated from the peripheral concentration curves (Table 1). There is no significant relation, either between the different phases of IRI output (basal rate, 1-10 min, 10-60 min), or between the IRI output on the one hand and the areas of IRI and BG or the glycemic assimilation constants on the other hand. Only the pancreatic IRI delivery rate in the anaesthetized fasted animal before any glucose injection is negatively correlated to the glucose assimilation constant $(p<0.05)$.

The 10-60 min IRI areas, but not those from 1-10 $\mathrm{min}$, are positively correlated with the BG areas $(p<, 0.05)$ : after the distribution of the injected glucose the amount of IRI reaching the peripheral circulation seems to increase with $\mathrm{BG}$.

\section{Discussion}

The experimental design reported here allows repeated estimation of IRI output rate during one in-vivo test. In contrast to the drainage methods, normal flow regulation and vascular integrity of the pancreas are preserved. The values represent the function of the whole organ (not only of one of its vascular regions). The estimated amounts of IRI output for anaesthetized dogs are comparable to the calculations by indirect methods of other authors [11, 20, 44]: $11-12 \mathrm{mU} / \mathrm{min}$. The values obtained by drainage or bypass methods are considerably smaller, even in relation to the mean body weight (given in brackets) of the experimental animals used: Bor et al. [5] - $3.6 \mathrm{mU} / \mathrm{min}(15-20 \mathrm{~kg})$, Lefèbvre et al. [24] $4.4 \mathrm{mU} / \mathrm{min}(15-22 \mathrm{~kg})$, Kanazawa et al. [21] - 3.9 $\mathrm{mU} / \mathrm{min}(9-29 \mathrm{~kg})$, Mandelbaum et al. [28] - 1.9 $\mathrm{mU} / \mathrm{min}(15-20 \mathrm{~kg})$, Bergman et al. [3] -0.9 $\mathrm{mU} / \mathrm{min}(2-3 \mathrm{~kg})$, Loubatières et al. [27] -4.0 $\mathrm{mU} / \mathrm{min}$ and Porte et al. [33] - $2.5 \mathrm{mU} / \mathrm{min}$ $(15 \mathrm{~kg})$. Some of the values referred to were converted or they were taken from figures. The differences from the findings reported here can be accounted for by methodologic advantages in relation to the venous drainage methods, which are discussed in detail by Fischer et al. [12].

Peripheral venous IRI concentrations are widely used as diagnostic criteria in tests of endocrine pancreatic function and of glucose tolerance. Despite several typical reaction patterns, their interpretation is difficult. According to our findings on anaesthetized animals, in the normal range such measurements give a rough correlation to $\mathrm{IRI}_{\text {port }}$ or to pancreatic IRI output.

Similar results were obtained by Cerasi and Luft [8] in man. In the individual case these values do not reflect the IRI secretion rate neither quantitatively nor qualitatively $[2,10,18,19,26]$. The lack of an exact relationship is due to the obligatory but inconstant metabolic loss of insulin in its passage through the liver $[11,16]$, and it is also due to the alteration of the pancreatic blood flow [14].

Some influence of pancreatic blood flow on the dynamics of insulin secretion can be observed when, during the measurement, the circulation is altered. Different secretory tests produce different variations of the pancreatic flow. They depend on simultaneous alterations of plasma osmolality (own unpublished results). During food ingestion as well as in an oral glucose load, some redistribution of splanchnic flow is to be expected $[6,23,35,36]$. - Redistribution of flow within the pancreas between its exocrine and endocrine parts can also be expected under the influence of insulinogenic stimuli [42]. The method used here for calculation of IRI output, however, does not depend on such variations of the pancreatic microcirculation.

Glucose is well recognized as the major physiologic 
stimulus acting directly on insulin secretion and there is a close relation between any alteration of $B G$ and of insulin secretion $[4,22,29]$. In several cases this connection could also be demonstrated when using peripheral venous concentrations for mathematical evaluation $[1,17,34]$.

In our experiments, such correlation appears independent of the use of the concentrations or of the amounts of glucose for correlation analysis. The correlation between IRI output and BG differs, however, in dependence on the test phase. This is demonstrated by the ratios of IRI output to glucose supply and to BG concentration, showing a biphasic alteration. During the early test phase with an extremely increased apparent IRI output, there is no alteration, or a small one only, of IRI delivered by the pancreas per mol glucose reaching it. In the later phase, this ratio is at least twice that of the pretest levels. These completely different phases are not clearly indicated by the computed IRI secretion rate because there is no steady state level of $B G$ and of IRI. Both these periods seem to correspond to the well known biphasic pattern of peripheral IRI concentration after several loads stimulating insulin secretion [8].

Relations between BG-dependent parameters and insulin secretion were observed in all statistical analyses performed. However, increased amounts of secreted IRI did not produce an increased action of insulin on BG level, glucose tolerance or glucose assimilation $[10,40]$. In man, a defective early phase IRI increase may indicate pre-diabetes $[7,8]$; and Lerner et al. [25] showed some interaction between the early IRI increase and the glucose assimilation constants. Other authors found no correlation, or a contrary one, between such parameters in the peripheral blood $[1,30,39,40]$. In our experiments, there was also no proof that a higher IRI concentration or output in the early or in the late phase is

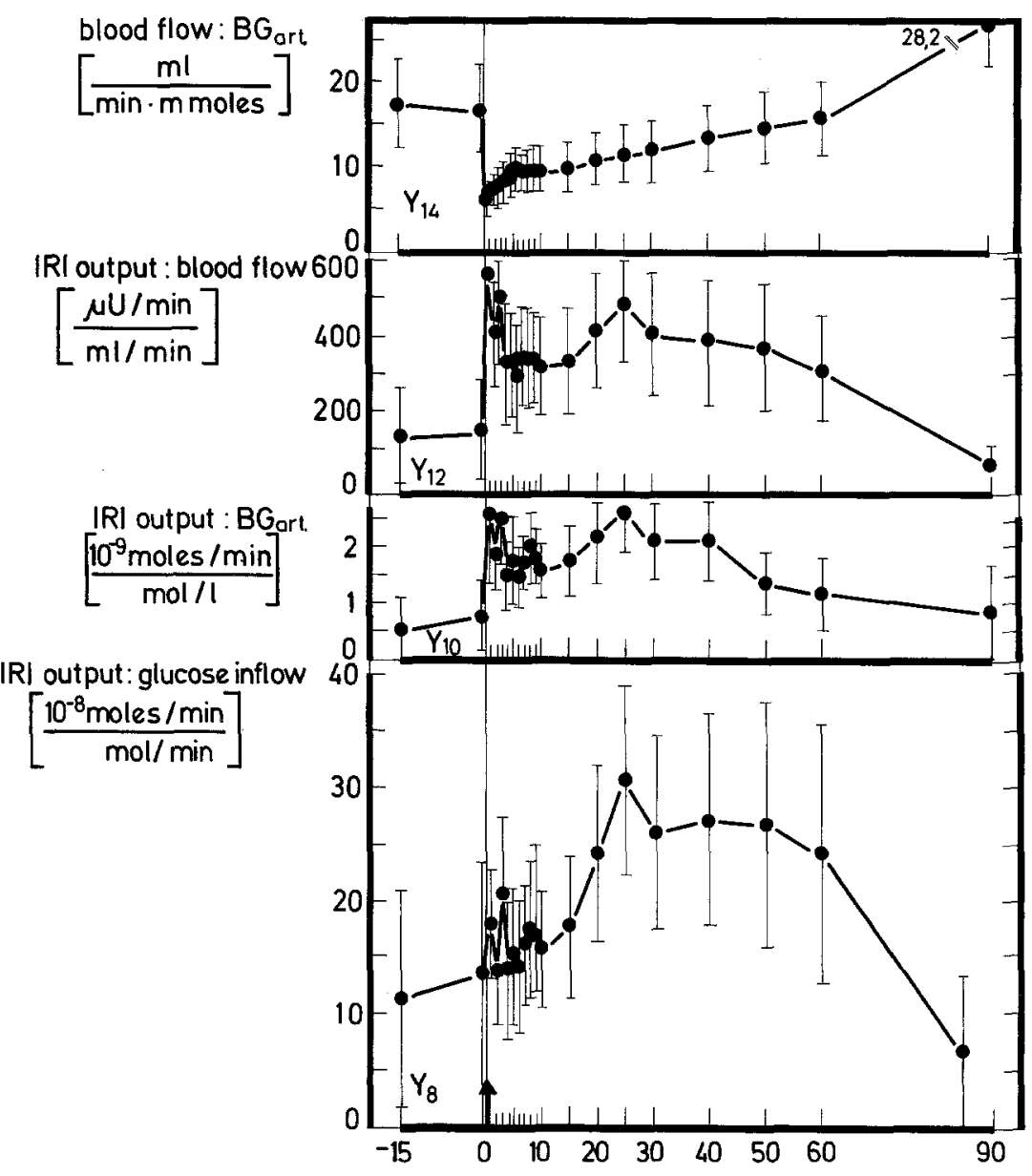

Fig. 5. Ratios of net pancreatic IRI output to BG, pancreatic inflow of glucose, or pancreaticoduodenal blood flow and of blood flow to BG in 7 anaesthetized dogs before and after i. v. injection of $0.5 \mathrm{~g} / \mathrm{kg}$ glucose. For molar ratios a molecular wt. of 6000 of IRI has been assumed 
followed by lower BG values or by an enhanced arteriovenous difference (unpublished data).

Any action of newly secreted insulin on glucose metabolism can possibly only be demonstrated by the glucose appearance and disappearance rates after injection of labelled substrates. - Thus, the pancreatic IRI output before the test is negatively correlated with the glucose assimilation constants which means that

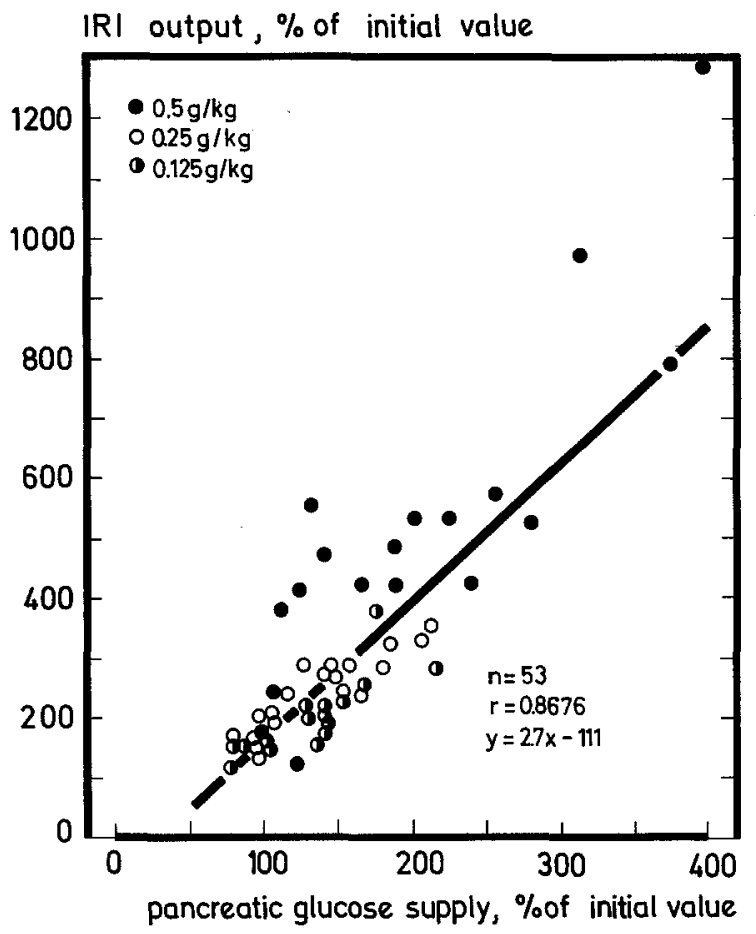

Fig. 6. Correlation of relative pancreatic glucose supply with net pancreatic IRI output after rapid i.v. injection of different doses of glucose. Each point represents the mean of one dose related group at a given time after the injection. $100 \%=$ mean of the -15 and -1 min-values in the individual experiments the higher the insulin secretion in the resting and fasting anaesthetized animal the lower is the ability to assimilate an exogenous glucose load. Similar conclusions could be drawn from peripheral IRI analyses in diabetic and normal men [31].

Acknowledgement. For skilful technical assistance we are grateful to Mrs. Karla Brüllke, Mrs. Helga Schröder, Mrs. Helga Goraczka and Mrs. Hannelore Buff.

\section{References}

1. Abraira, C., Goldstein, M.C.: Acute glucose loads in insulinized pancreatectomized dogs. J. Lab. clin. Med. 81, 696-703 (1973)

2. Berger, W., Goeschke, H., Moppert, J., Kuenzli, H.: Insulin concentrations in portal venous and peripheral venous blood in man following administration of glucose, galactose, xylitol and tolbutamide. Horm. Metab. Res. 5, 4-8 (1973)

3. Bergman, R.N., Miller, R.E.: Direct enhancement of insulin secretion by vagal stimulation of the isolated pancreas. Amer. J. Physiol. 225, 481-486 (1973)

4. Bergman, R.N., Urquhart, J.: The pilot gland approach to the study of insulin secretory dynamics. Recent Progr. Hormone Res. 26, 583-605 (1971)

5. Bor, N.M., Ercan, M.T., Alvur, M., Bekdek, C., Oner, G.: Calculation of net insulin secretion and pancreatic blood flow. Pflügers Arch. ges. Physiol 352, 179-188 (1974)

6. Bynum, T.E., Jacobson, E. D.: Blood flow and gastrointestinal function. Gastroenterology 60, 325-335 (1971)

7. Cerasi, E., Hallberg, D., Luft, R.: Simultaneous determination of insulin in brachial and portal vein during glucose infusion in normal and prediabetic subjects. Horm. Metab. Res. 2, 303-304 (1970)

8. Cerasi, E., Luft, R.: The plasma insulin response to glucose infusion in healthy subjects and in diabetes mellitus. Acta endocr. 55, 278-304 (1967)

9. Conard, V., Franckson, J.R.M., Bastenie, B.A., Kestens, J., Koracz, L.: Étude critique du triangle d'hyperglycémie intraveineux chez l'homme normal et détermination d'un "coefficient d'assimilation glycidique". Arch. int. Pharmacodyn. 43, $132-134(1953)$

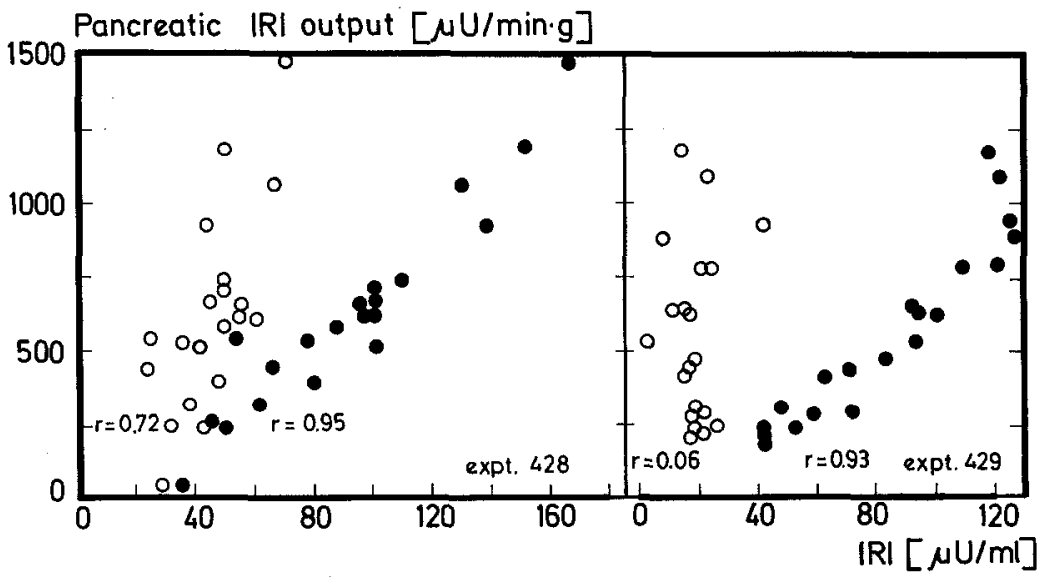

Fig. 7. Relations of $\operatorname{IRI}_{\text {port }}(\bullet)$ and $\operatorname{IRI}_{\text {ven }}(0)$ to net pancreatic IRI output in 2 selected experiments, i.v. injection of $0.25 \mathrm{~g} / \mathrm{kg}$ glucose. Left side: expt. 428, significant correlation of both IRI conentrations to output. Right side: expt. 429 , significant correlation of IRI port $_{\text {only to the }}$ output 
10. Federspil, G., Casara, D., Pedrazzoli, S., Sicolo, N., Scandellari, C.: In vivo studies on 5-Hydroxytryptamine and insulin secretion in dogs and in man. Diabetologia 10, 13-17 (1974)

11. Field, J.B.: Insulin extraction by the liver. In: Handbook of physiology, Sect. 7: Endocrinology, Vol. II: Endocrine Pancreas. (eds. D. F. Steiner, N. Freinkel), pp. 505-573. Washington: Amer. Physiol. Soc., 1972

12. Fischer, U., Hommel, H., Jutzi, E., Fiedler, H.: Modell der Netto-Insulinabgabe des Pankreas in vivo. Acta biol. med. germ. 33, 21-34 (1974)

13. Fischer, U., Hommel, H., Orosz, L., Fiedler, H.: Einfluß von Narkose und Heparin auf die glukoseinduzierte Insulinsekretion bei Hunden. Endokrinologie 60, 17-26 (1972)

14. Fischer, U., Hommel, H., Schmid, E.: Continous registration of the pancreatic blood flow after intravenous application of glucose. Experientia (Basel) 29, 884-885 (1973)

15. Fischer, U., Hommel, H., Ziegler, M., Michael, R.: The mechanism of insulin secretion after oral glucose administration. I. Multiphasic course of insulin mobilization after oral administration of glucose in conscious dogs. Difference to the behaviour after intravenous administration. Diabetologia 8, 104-110 (1972)

16. Franckson, J.R.M., Ooms, H.A.: The catabolism of insulin in the dog: Evidence for the existence of two catabolic pathways. Postgrad. med. J. 49, $931-939$ (1973)

17. Hetenyi, G., Jr., Norwich, K.H., Zelin, S.: Analysis of the glucoregulatory system in dogs. Amer. J. Physiol. 224, 635-642 (1973)

18. Hiebert, J.M., McCormick, J.M., Egdahl, H.E.: Direct measurement of insulin secretory rate: studies in shocked primates and postoperative patients. Ann. Surg. 176, 296-303 (1972)

19. Hiebert, J.M., Sixt, N., Soeldner, J.S., Egdahl, R.H.: Altered insulin and glucose metabolism produced by epinephrine during hemorrhagic shock in adrenalectomized primate. Surgery 74, 223-234 (1973)

20. Kaden, M., Harding, P., Field, J.B.: Effect of intraduodenal glucose administration on hepatic extraction of insulin in the anaesthetized dog. J. clin. Invest. 52, 2016-2028 (1973)

21. Kanazawa, Y., Kuzuya, R., Ide, T.: Insulin output via the pancreatic vein and plasma insulin response to glucose in dogs. Amer. J. Physiol. 215, 620-626 (1968)

22. Kidson, W., Lazarus, L.: The glycaemic stimulus to early phase insulin release: quantitation of beta cell function. Horm. Metab. Res. 5, 387-391 (1973)

23. Kuznetsova, K.E.: Characteristics of blood supply of the pancreas during different phases of its activity. Fed. Proc. 22, T99- 104 (1963)

24. Lefèbvre, P.J., Luyckx, A.S.: Stimulation of insulin secretion after prostaglandin $\mathrm{PGE}_{1}$ in anaesthetized dog. Biochem. Pharmacol. 22, 1773-1779 (1973)

25. Lerner, R.L., Porte, D., Jr.: Relationship between intravenous glucose loads, insulin responses and glucose disappearence rate. J. clin. Endocr. 33, 409-417 (1971)

26. Lohmann, D., Gentzsch, R., Engel, K., Gläser, A., Schönfelder, M.: Einfluß der Leber auf den Seruminsulinspiegel. Dtsch. Z. Verdau.- u. Stoffwechselkr. 33, 185-191 (1973)

27. Loubatières, A., Mariani, M.M., Sorel, G., Savi, L.: The action of beta-adrenergic blocking and stimulating agents on insulin secretion. Characterization of the type of beta-receptor. Diabetologia 7, 127-132 (1971)

28. Mandelbaum, J., Morgan, C.L.: Pancreatic blood flow and its relationship to insulin secretion during extracorporeal circulation. Ann. Surg. 170, 753-758 (1969)

29. Marliss, E.B., Girardier, L., Seydoux, J., Wollheim, C.B., Ka- nazawa, Y., Orci, L., Renold, A.E., Porte, D., Jr.: Glucagon release induced by pancreatic nerve stimulation in the dog. $\mathrm{J}$. clin. Invest. 52, 1246-1259 (1973)

30. Meade, R.C., Kneubuhler, H.A., Barboriak, J.J., Schulte, W.J.: Absence of glucose response to physiologic levels of serum insulin. Diabetes 18, 397-401 (1969)

31. Olefsky, J., Farquhar, J.W., Reaven, G.M.: Relationship between fasting plasma insulin level and resistance to insulin-mediated glucose uptake in normal and diabetic subjects. Diabetes 22, 507-513 (1973)

32. Orosz, L., Fischer, U., Hommel, H., Fiedler, H.: Direkte Hemmwirkung des Heparins auf die Insulinsekretion. Experientia (Basel) 28, 158-159 (1972)

33. Porte, D., Jr., Girardier, L., Seydoux, J., Kanazawa, Y., Posternak, J.: Neural regulation of insulin secretion in the dog. J. clin. Invest. 52, 210-214 (1973)

34. Reaven, G.M., Farquhar, J.W.: Steady state plasma insulin response to continuous glucose infusion in normal and diabetic subjects. Diabetes 18, 273-279 (1969)

35. Rérat, A.: Measurement of the portal blood flow in the pig by means of an electromagnetic flowmeter. Ann. Biol. anim. 11, $175-180$ (1971)

36. Rushmer, R.F., Franklin, D.L., van Citters, R. L., Smith, O. A.: Changes in peripheral blood flow distribution in healthy dogs. Circulat. Res. 9, 675-687 (1961)

37. Schenk, W.G., Jr., Dedichen, H.: Measurement of blood flow. Amer. J. Surg. 114, 111-118 (1967)

38. Stern, M.P., Farquhar, J. W., Silvers, A., Reaven, G. M.: Insulin delivery rate into plasma in normal and diabetic subjects. J. clin. Invest. 47, 1947-1957 (1968)

39. Thorell, J.I: : Effect of transient elevation of plasma insulin within physiologic levels (stimulated early insulin response) on blood glucose. J. clin. Endocr. 37, 423-430 (1973)

40. Thorell, J.I., Nosslin, B., Sterky, G.: Estimation of the early insulin response to intravenous glucose injection. J. Lab. clin. Med. 82, $101-110$ (1973)

41. Turner, R.C., Grayburn, J.A., Newman, G.B., Nabarro, J.D. N.: Measurement of the insulin delivery rate in man. J. clin. Endocr. 33, 279-286 (1971)

42. Vance, J.E.: Insulin release and changes in the capillary circulation of the pancreas. Diabetes 19, Suppl. 1 (abstr.), 402 (1970)

43. Varandani, P.T.: Insulin degradation. VI. Feedback control by insulin of liver glutathione-insulin transhydrogenase in rat. Diabetes $23,117-125$ (1974)

44. Vranic, M., Wrenshall, G.A.: Matched rates of insulin infusion and secretion and concurrent tracer-determined rates of glucose appearence and disappearence in fasting dogs. Canad. J. Physiol. Pharmacol. 46, 383-390 (1968)

45. Wrenshall, G.A., Bogoch, A., Ritchie, R.C.: Extractable insulin of pancreas. Correlations with pathological and clinical findings in diabetic and nondiabetic cases. Diabetes 1, $87-105$ (1952)

46. Zöllner, N., Marshall, M., Doerfler, H., Wolfram, G.: Arterielle Insulinspiegel nach intravenöser Zufuhr eines Sulfonylharnstoffpräparates. Vorversuche zur quantitativen Analyse der frühen Insulinsekretionsphase. Z. ges. exp. Med. exp. Chir. 153, 269-272 (1970)

Dr. med. U. Fischer

Zentralinstitut für Diabetes

"Gerhard Katsch"

Bereich experimentelle Forschung

DDR-2201 Karlsburg

Germany 